\title{
Effect of dental implant angulation on the dimensional accuracy of master casts
}

\author{
Negar Barjini ${ }^{1, A, D-F}$, Sahar Sayahpour ${ }^{2, B, C, F}$, Maryam Jafari ${ }^{3, D-F}$ \\ ${ }^{1}$ Department of Prosthodontics, Dental Caries Prevention Research Center, Qazvin University of Medical Sciences, Iran \\ 2 Private practice, Tehran, Iran \\ ${ }^{3}$ Post-graduate student, Student Research Committee, Qazvin University of Medical Sciences, Iran \\ A - research concept and design; B - collection and/or assembly of data; $\mathrm{C}$ - data analysis and interpretation; \\ $D$ - writing the article; $E$ - critical revision of the article; $F$ - final approval of the article
}

Address for correspondence

Sahar Sayahpour

E-mail:Sayahpour.dds@gmail.com

\section{Funding sources}

None declared

Conflict of interest

None declared

Received on August 23, 2020

Reviewed on January 29, 2021

Accepted on March 3, 2021

Published online on December 31, 2021

Cite as

Barjini N, Sayahpour S, Jafari M. Effect of dental implant angulation on the dimensional accuracy of master casts. Dent Med Probl. 2021;58(4):473-482. doi:10.17219/dmp/133894

DOI

10.17219/dmp/133894

Copyright

๑ 2021 by Wroclaw Medical University

This is an article distributed under the terms of the

Creative Commons Attribution 3.0 Unported License (CC BY 3.0)

(https://creativecommons.org/licenses/by/3.0/).

\section{Abstract}

Background. Making accurate impressions of dental implants and transferring their three-dimensional (3D) position to master casts is critical for the passive fit of prosthetic frameworks.

Objectives. This study aimed to assess the effect of dental implant angulation on the dimensional accuracy of master casts.

Material and methods. An acrylic model with 2 external hexagonal implants was used in this in vitro experimental study. The impressions of the model were made in 42 positions, with different angulation of the 2 implants, ranging from $+15^{\circ}$ to $-15^{\circ}$, by means of the open-tray and closed-tray impression techniques, using a polyvinyl siloxane impression material. The spatial coordinates of the implants were measured on the $X, Y$ and $Z$ axes. The dimensional accuracy of the impressions made at different positions (parallel, convergent and divergent) and different angulation of the implants were determined. The data was analyzed using the one-way analysis of variance (ANOVA), Student's t test and Tukey's test.

Results. Casts with the lowest accuracy were obtained when the 2 implants were divergent by $25^{\circ}$ $(R=1.1336)$. However, the position of the 2 implants had no significant effect on the dimensional accuracy of the master casts. The error rate was 0.4181 in the open-tray technique and 0.5095 in the closed-tray technique, with no significant difference between them $(p>0.05)$. The angulation of the $2 \mathrm{implants}$ had a significant effect on the dimensional accuracy of the master casts $(p=0.0001)$.

Conclusions. Considering the significant effect of implant angulation in the range from $+15^{\circ}$ to $-15^{\circ}$ relative to the longitudinal axis on the dimensional accuracy of master casts, further studies are required to reach a final conclusion in this respect.

Keywords: dental implants, dimensional accuracy, dental impression technique, dental implant angulation, master cast 


\section{Introduction}

Dental implants are presently in high demand. Due to the high success rate of implant treatment, implantsupported restorations are the first choice for prosthetic treatment. ${ }^{1}$ Biomechanically, implant-supported restorations are fabricated with the aim of achieving passive fit in the attachment of abutments and fixtures. Passive fit is imperative to ensure equal stress distribution at the bone-implant interface. Precise clinical and laboratory steps are taken to achieve passive fit. ${ }^{2}$ Misfit would cause internal stresses, and their subsequent transfer to implants and the bone matrix. ${ }^{3}$ In the fabrication of implant-supported restorations, the accurate transfer of the intraoral position of the implant to the cast is much more important than it is for natural teeth. ${ }^{4}$ In these restorations, the applied physiological forces are transferred to the surrounding bone in a manner that is similar to what occurs in natural teeth. ${ }^{5}$ However, due to the absence of the periodontal ligament around a dental implant, misfit can result in destructive stresses in the bone-implant complex. ${ }^{3}$ Moreover, evidence shows that the absence of passive fit in implant-supported restorations can cause tiny bone fractures or ischemic marginal zones. The healing of these lesions involves the formation of fibrous connective tissue at the bone-implant interface and prevents osseointegration or causes periimplant bone loss. ${ }^{5}$

Framework misfit can cause biological and biomechanical problems. The application of excessive load, exceeding the physiological threshold of the implant-supporting bone, can cause pain, tissue irritation, marginal bone loss, and impaired osseointegration. ${ }^{4,6}$ The mobility and fractures of implant components are among biomechanical problems that may occur. ${ }^{7,8}$

Moreover, active fit is the primary cause of the mobility of restorations, abutment screw loosening, bone loss, and the fractures of implant components. ${ }^{9}$ The amount of stress that can clinically compromise the long-term stability of implants has not been determined. ${ }^{10}$ It seems that accurate impression making, the safe transfer of the impression to the laboratory without distortion and the fabrication of an accurate model are important to achieve passive fit. ${ }^{11}$ The first step is to precisely record the position of the implant in the oral cavity and transfer it to the cast by making an accurate impression. ${ }^{12}$ However, in all impression techniques, a range of errors may occur in the transfer of the implant position, and the elimination of errors in impression making is not clinically feasible. ${ }^{13}$ As mentioned, impression making is an important step in the fabrication of implant-supported restorations. It plays a fundamental role in obtaining the dimensional accuracy of the final cast. ${ }^{4,14}$ However, it should be noted that when the angulation or position of the implant are incorrect, the impression making process is difficult, and requires more time and higher precision. ${ }^{15}$
Considering the controversy regarding the dimensional accuracy of different impression techniques and the gap of information on the selection of the best impression technique for angulated implants, further studies on this topic seem imperative. This study aimed to assess the effect of dental implant angulation on the dimensional accuracy of master casts.

\section{Material and methods}

In this in vitro study, the impression of the mandible of a 53-year-old patient was made. The patient had implants at the sites of teeth 29 and 31. A special tray was custommade for this patient. An accurate impression was made and a dental stone cast was fabricated. The master model was prepared by duplicating the stone cast and pouring an acrylic resin (Lucitone ${ }^{\circledR}$ Clear; Dentsply International, York, USA). At the art portion of the master model, 3 tray stops were fabricated. It should be noted that this model did not have teeth $17,29,30,31$, and 32 , according to the Universal Numbering System. Also, at the sites of teeth 18, 19 and 28, metal balls with a diameter of $3 \mathrm{~mm}$ were incorporated, acting as reference points in measurements.

A metal device was designed to adjust the different angles of the impression copings. The device consisted of 2 stainless steel plates connected to each other by means of 3 vertical rods (Fig. 1). The upper plate measured $198 \mathrm{~mm}$ in length, $151.5 \mathrm{~mm}$ in width and $10.3 \mathrm{~mm}$ in height. The lower plate measured $197.5 \mathrm{~mm}$ in length, $151.2 \mathrm{~mm}$ in width and $18.73 \mathrm{~mm}$ in height. Two of the connecting rods located at the sides of the device had a diameter of $20 \mathrm{~mm}$ and a length of $163.5 \mathrm{~mm}$, while the third rod was at the front, and measured $10 \mathrm{~mm}$ in diameter and $101 \mathrm{~mm}$ in length. In the lower plate, 2 holes with a diameter of $20 \mathrm{~mm}$ were made to pass the 2 side rods and connect them to the upper plate. A number 6 screw was used to tighten the rods. Both of the rods passed through the upper plate, with $3 \mathrm{~cm}$ of the end part of them sticking out of the device. To prevent errors, a number 18 screw was placed over the rods to tighten them (Fig. 2).

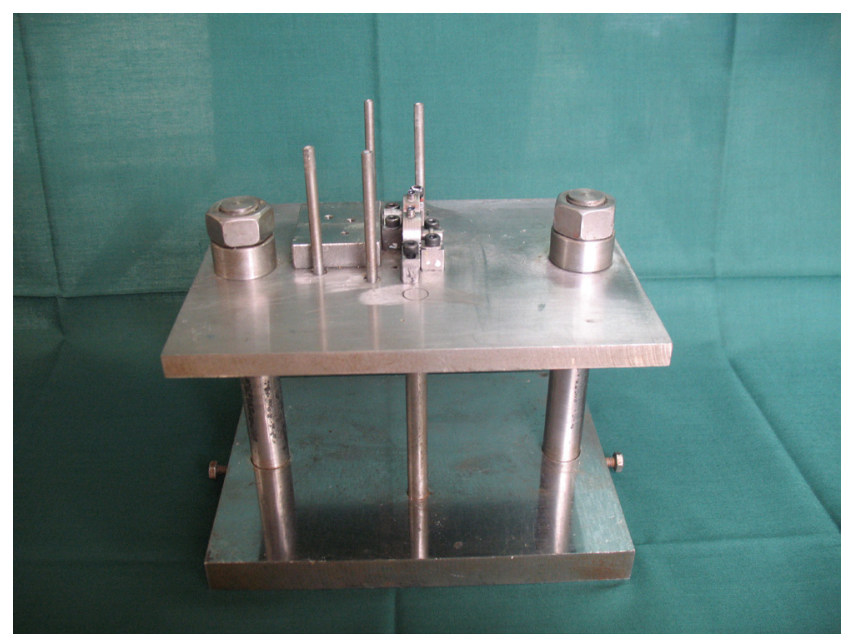

Fig. 1. Device used in the study 


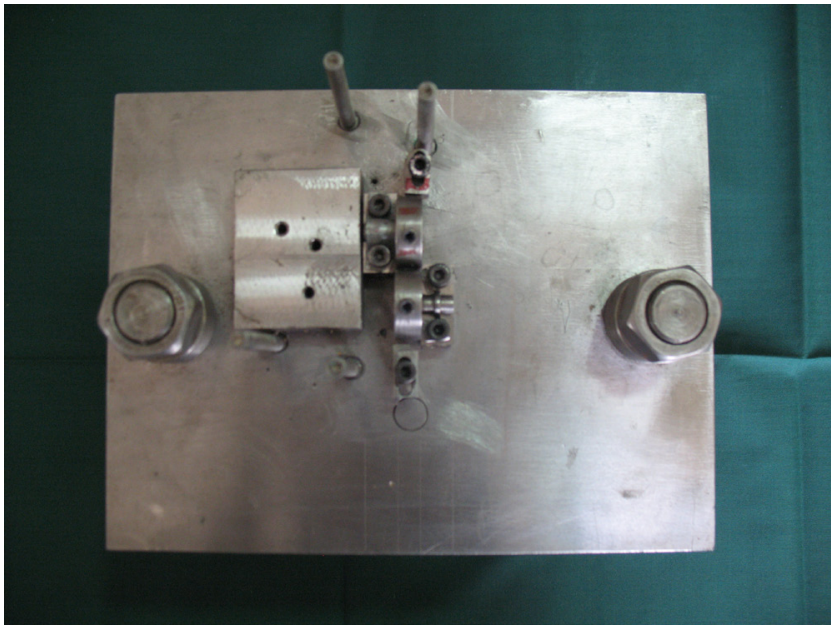

Fig. 2. Top view of the device

This device had 2 implant holders at the sites of teeth 29 and 31, which allowed changing the angulation of the implants. The implant holders were located on 2 spherical metal components measuring $22 \mathrm{~mm}$ in diameter and $8 \mathrm{~mm}$ in thickness. The location of an 8-millimeter-deep implant hole was determined using a surveyor with its axis directed at the center of the implant hole (Fig. 3). Shafts measuring $8 \mathrm{~mm}$ in larger diameter and $6 \mathrm{~mm}$ in smaller diameter were designed for the mobilization of the 2 described components. The assembly of the spherical metal component and the shaft was placed on a base measuring $25 \mathrm{~mm}$ in length, $10 \mathrm{~mm}$ in width and $11.5 \mathrm{~mm}$ in height. Two number 4 screws on each base attached them to the upper plate. For a better placement of the bases on the plate, 2 plates measuring $25 \mathrm{~mm}$ in length, $10 \mathrm{~mm}$ in width and $1 \mathrm{~mm}$ in depth were created and positioned lower than the level of the upper plate.

A plate measuring $50 \mathrm{~mm}$ in length, $40 \mathrm{~mm}$ in width and $12.3 \mathrm{~mm}$ in height was used to level the position of the master model and the implant holders. Four number 4 vertical rods were used around the master model

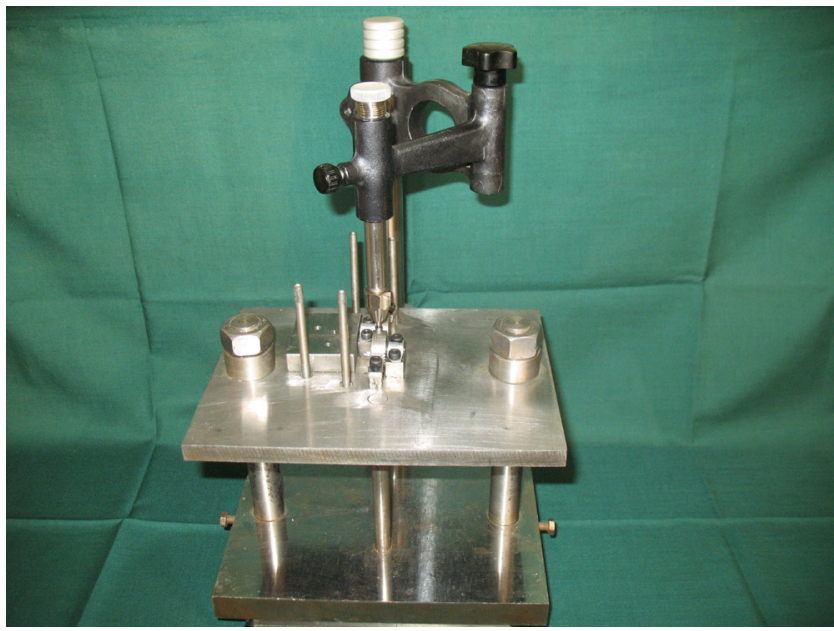

Fig. 3. Accommodating the implant axe to the center of the implant hole by means of a surveyor on the device to standardize the path of insertion and retrieval of the tray (Fig. 4).

The implant holders were designed so that they could angulate each implant relative to the vertical axis (perpendicular to the occlusal plane and the device) by $0^{\circ}, \pm 5^{\circ}$, $\pm 10^{\circ}$, and $\pm 15^{\circ}$. The center of rotation of both implant holders, which corresponded to the implant apex, was at the same level. To fix the desired angle, the position of both implant holders was secured with a metal blade. The 2 external hexagonal implants placed in the implant holders measured $4 \mathrm{~mm}$ in diameter and $15 \mathrm{~mm}$ in length (OSS415; Implant Innovations Inc., Palm Beach Gardens, USA). The impression of the master model was made using a prefabricated tray and an additional silicone impression material (A-Silicone; Zhermack, Badia Polesine, Italy), and the primary cast was poured. Two layers of base plate wax (TruWax ${ }^{\circledR}$; Dentsply Trubyte, York, USA) were applied on the cast except for the stop points. ${ }^{8,13}$ The cast was duplicated and turned into a stone model to standardize the space for the fabrication of trays for all samples. A light-cured acrylic resin (Preci-Tray; YETI Dental, Engen, Germany) was used for the fabrication of trays.

To fabricate a special tray for the open-tray impression technique, all of the aforementioned steps were repeated following the placement of the direct impression copings on the primary cast. Holes with a diameter of $3 \mathrm{~mm}$, a 0.5 -centimeter distance from each other and a wing were created on special trays. There were 2 holes at each side (a total of 4 ). The 4 vertical rods were passed through the 4 holes to determine the path of insertion of the tray. A metal plate weighing $430 \mathrm{~g}^{16}$ was placed over the wing during the setting of the impression material to simulate hand pressure. The 2 implants could have 42 different positions relative to each other, with different angulation, including 6 angles for implant 5 and 7 angles for implant $7: 0^{\circ}, \pm 5^{\circ}$ and $\pm 10^{\circ}$ relative to the vertical axis for both implants; $\pm 15^{\circ}$ for the implant at the site of tooth 31 (implant 7 ), and $-15^{\circ}$ for the im-

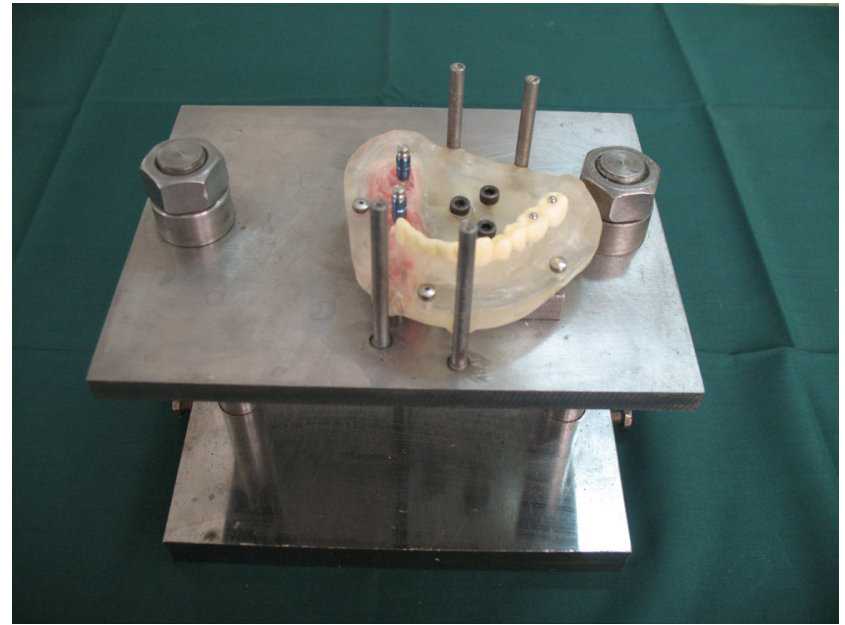

Fig. 4. Acrylic model on the device and the vertical guiding rods around it 
plant at the site of tooth 29 (implant 5). Before making any impressions, the open and closed impression copings were attached to the implants of the master model. The basic three-dimensional (3D) measurements on the $\mathrm{X}, \mathrm{Y}$ and $\mathrm{Z}$ axes were performed using a coordinatemeasuring machine (CMM).

Before making the impression, a silicone adhesive material (Tray Adhesive; Zhermack) was applied on the internal margins and on $3 \mathrm{~mm}$ of the external margins of the fabricated tray, allowing $1 \mathrm{~min}$ to set, according to the manufacturer's instructions. A polyvinyl siloxane impression material (Monophase Medium Body, A-Silicone; Zhermack) was injected into the tray and around the impression copings (Fig. 5). The metal plate was placed over the wing, and the 4 vertical rods were passed through the 4 holes (Fig. 6). The tray stops matched the model stops and the tray was finally seated. After the final setting of the impression material, which took $5 \mathrm{~min}$ and $30 \mathrm{~s}$, as stated in the manufacturer's instructions, the tray was removed from the model.

In the open-tray technique (direct pick-up coping), the direct impression copings were unscrewed prior to the

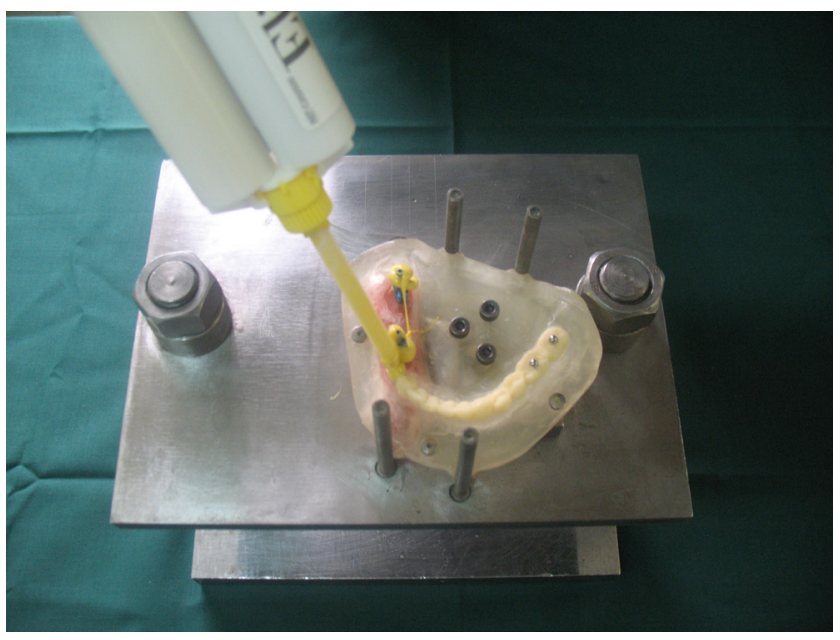

Fig. 5. Injecting the impression material over the copings

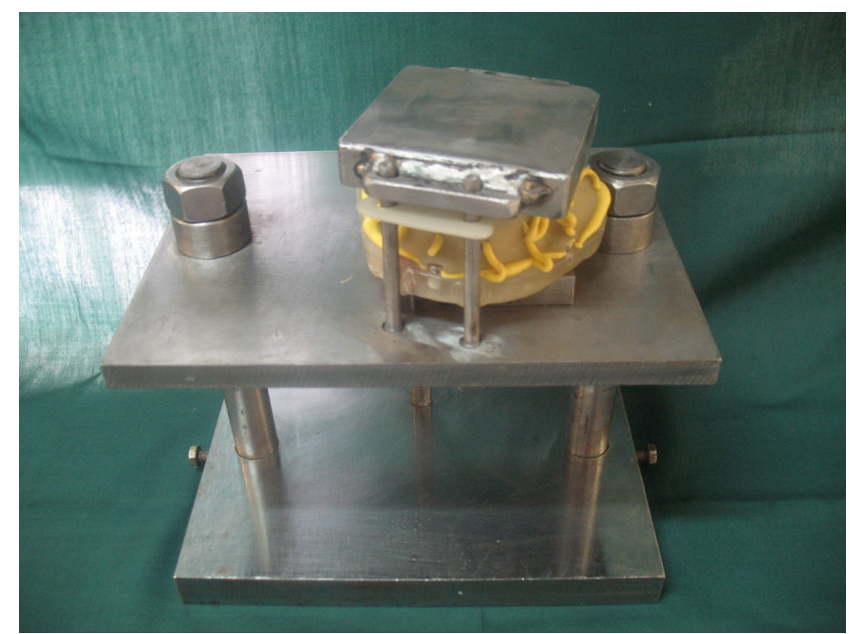

Fig. 6. Metal plate covering the wing during impression making removal of the impression and were separated from the model simultaneously with the removal of the impression (Fig. 7).

In the closed-tray technique (indirect transfer coping), the indirect impression copings were screwed into the implants, and after making the impression and separating them from the model, the copings were opened and attached to the implant analogs. The analog-coping complex was then placed in the impression.

Gingifast (Zhermack) was injected around the copings in the trays before pouring the casts. The metal balls were also placed at their respective locations in the impression. The final cast was poured with type IV dental stone (Zhermack) (Fig. 8). For the purpose of standardization, the powder to liquid ratio of the dental stone was determined according to the manufacturer's instructions, and mixing was performed with a vacuum mixer (Vac-U-Mixer; Whip Mix Corporation, Louisville, USA).

After the final setting of the gypsum (45 min), the final position of the 2 implants in the $\mathrm{X}, \mathrm{Y}$ and $\mathrm{Z}$ axes relative to the reference points was determined using CMM with an accuracy of $0.1 \mu \mathrm{m}$ (Fig. 9). A coordinate-measuring

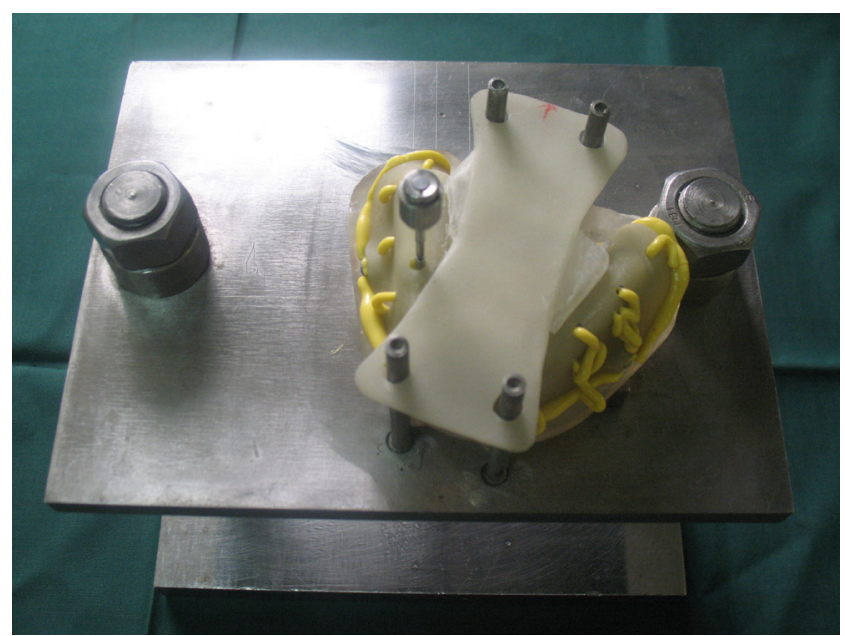

Fig. 7. Open-tray impression technique

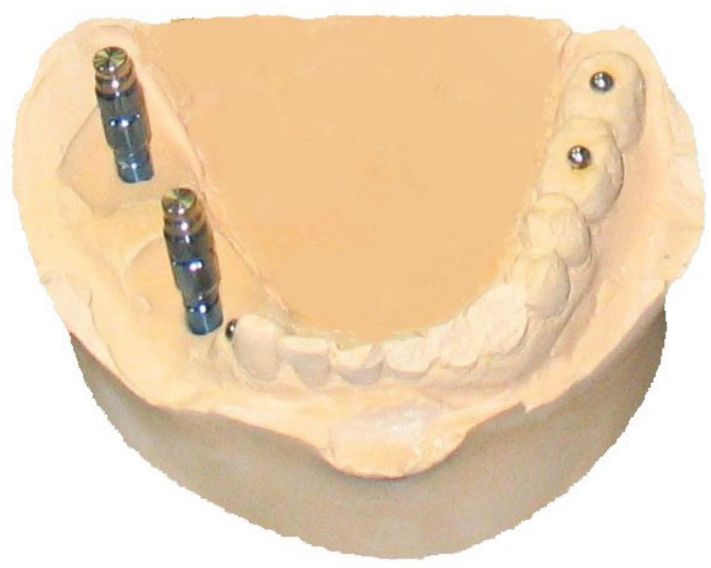

Fig. 8. Final cast 
machine is a high-precision contact instrument with a $1 \mathrm{~m} \times 1 / 8 \mathrm{~m}$ table and a sensitive probe that moves along the entire length and width of the table with 2 arms - vertical and horizontal. In a standard specific place on the table, there is a sphere with a fixed and reliable diameter so that the position of the probe and the tip size can be calibrated each time the probe is changed in terms of the 3 dimensions.

The sensitivity of the probe tip to contact is such that it measures the position of any point on the surface of an object relative to the standard sphere in the $\mathrm{X}, \mathrm{Y}$

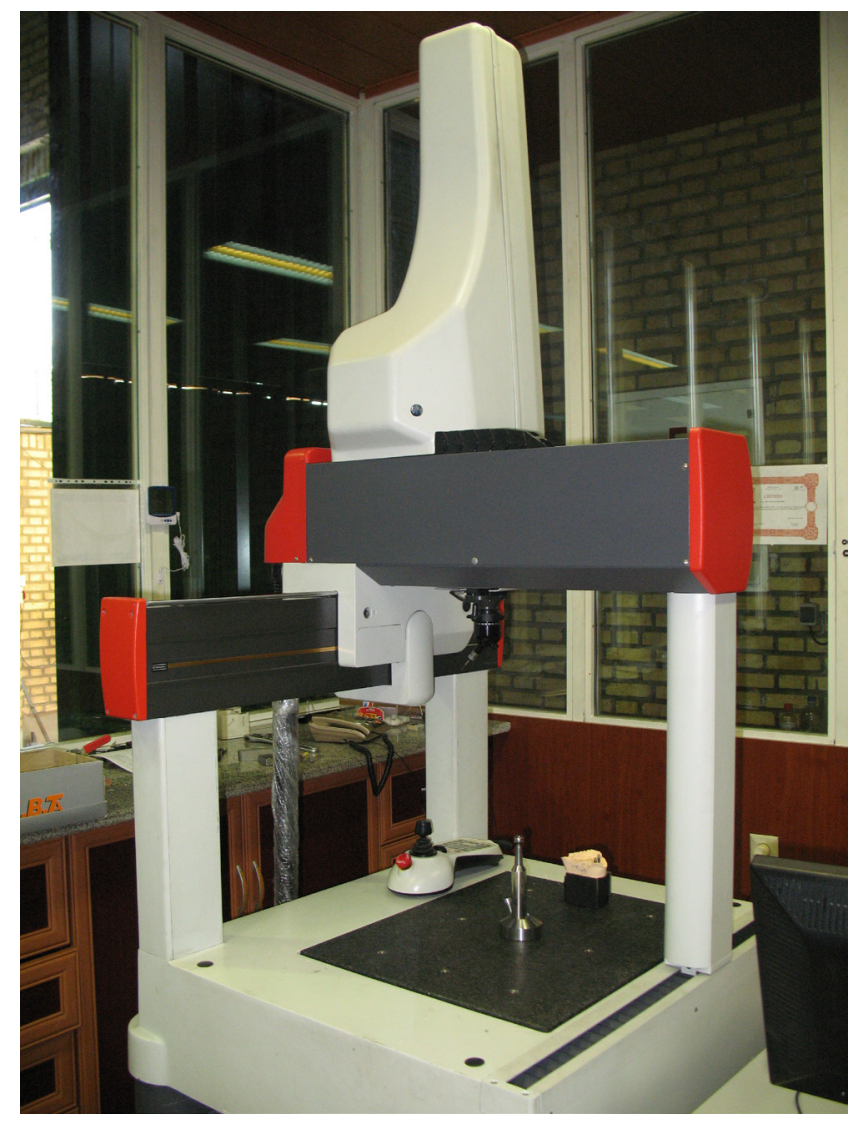

Fig. 9. Coordinate-measuring machine (CMM)

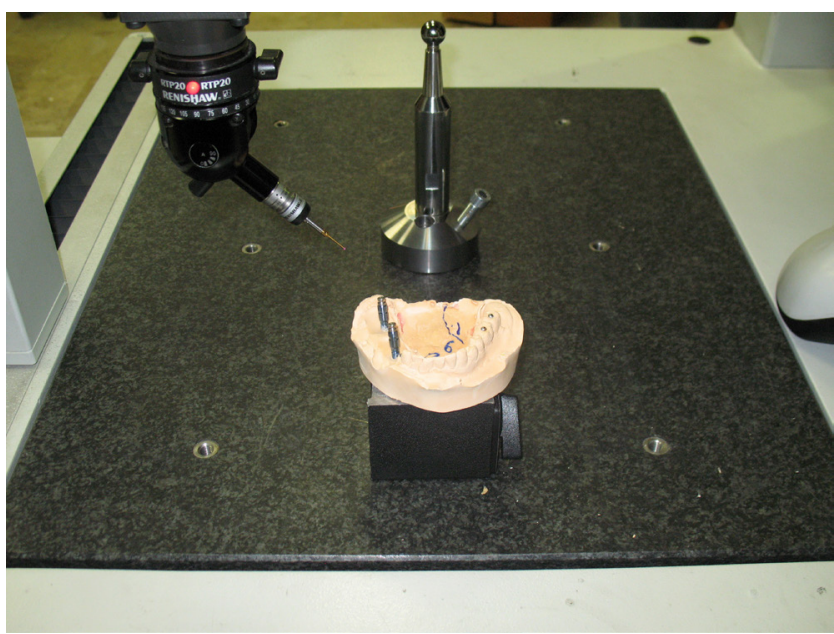

Fig. 10. Contact of the probe with the sphere and $\mathrm{Z}$ dimensions with an accuracy of $0.1 \mu \mathrm{m}$ over the entire area of the table. After providing settings and defining a spherical body by means of the Trimek software (Altube-Zuia, Spain), this device is able to specify the exact coordinates of the center of this sphere in relation to the standard sphere, and also indicate its out of sphericity (Fig. 10). In this study, the coordinates of the center of the direct and indirect impression copings relative to the 3 metal balls placed at the sites of teeth 18, 19 and 28 were determined in the 3 dimensions. The measurements were performed in triplicate, and the mean values were calculated and used for the statistical analysis.

\section{Statistical analysis}

The coordinates of the center of each implant in the 3 dimensions in different impression techniques and at different angulation were determined, and differences with regard to the reference points were calculated.

The data was analyzed using the IBM SPSS Statistics for Windows software, v. 25.0 (IBM Corp., Armonk, USA). Differences in the $\mathrm{X}, \mathrm{Y}$ and $\mathrm{Z}$ coordinates of the samples at different angulation, both in the open- and closed-tray techniques, were determined relative to the coordinates of the reference points, and the overall value in the 3 axes was calculated using the following formula (Equation 1):

$$
\Delta \mathrm{R}=\sqrt{(\Delta \mathrm{X})^{2}+(\Delta \mathrm{Y})^{2}+(\Delta \mathrm{Z})^{2}}
$$

where:

$\mathrm{R}$ - spatial position;

$\mathrm{X}, \mathrm{Y}, \mathrm{Z}$ - coordinates in the 3 axes.

This was considered to be the dimensional accuracy of each impression. The statistical analysis was carried out using the independent $t$ test and the one-way analysis of variance (ANOVA). Considering the significant effect of the angulation of the 2 implants relative to each other on the dimensional accuracy of the impressions, pairwise comparisons of different angulation were carried out using Tukey's test. A $p$-value $<0.05$ was considered statistically significant.

\section{Results}

The estimation of errors in the master cast in different implant positions revealed the maximum error in the parallel position of the 2 implants, when each of them was at an angle of $-10^{\circ}$ relative to the vertical axis $(R=1.3665)$. Also, the minimum error was noted when implant 5 was at an angle of $-15^{\circ}$ and implant 7 was at an angle of $10^{\circ}$ relative to the vertical axis of the implant $(R=0.0188)$.

The impression error values in the parallel states of the 2 implants as well as in their different convergences and divergences according to their angular positions are presented in Table 1. 
Table 1. Impression error values in the parallel, convergent and divergent positions of the 2 implants according to their angulation relative to the longitudinal axis

\begin{tabular}{|c|c|c|c|c|c|}
\hline \multirow[t]{2}{*}{ Position } & \multicolumn{2}{|c|}{$\begin{array}{c}\text { Angulation relative to } \\
\text { the longitudinal axis } \\
{\left[{ }^{\circ}\right]}\end{array}$} & \multirow[t]{2}{*}{ Number of positions } & \multirow[t]{2}{*}{ Impression error } & \multirow[t]{2}{*}{$p$-value } \\
\hline & implant 5 & implant 7 & & & \\
\hline \multirow{6}{*}{ Parallel } & 0 & 0 & 2 & $0.3104 \pm 0.04178$ & \multirow{6}{*}{0.059} \\
\hline & 5 & 5 & 2 & $0.7112 \pm 0.53412$ & \\
\hline & 10 & 10 & 2 & $0.0690 \pm 0.01858$ & \\
\hline & -5 & -5 & 2 & $0.1150 \pm 0.00000$ & \\
\hline & -10 & -10 & 2 & $1.3665 \pm 0.67123$ & \\
\hline & -15 & -15 & 2 & $0.8849 \pm 0.13626$ & \\
\hline \multirow{6}{*}{$5^{\circ}$ convergence } & 0 & 5 & 2 & $0.4360 \pm 0.00994$ & \multirow{6}{*}{$<0.001^{*}$} \\
\hline & -5 & 0 & 2 & $0.0662 \pm 0.02394$ & \\
\hline & 5 & 10 & 2 & $0.9317 \pm 0.16470$ & \\
\hline & 10 & 15 & 2 & $0.0739 \pm 0.01089$ & \\
\hline & -10 & -5 & 2 & $0.0229 \pm 0.01042$ & \\
\hline & -15 & -10 & 2 & $0.7555 \pm 0.05273$ & \\
\hline \multirow{5}{*}{$10^{\circ}$ convergence } & 0 & 10 & 2 & $0.2524 \pm 0.01513$ & \multirow{5}{*}{$<0.001^{*}$} \\
\hline & -10 & 0 & 2 & $0.0614 \pm 0.00740$ & \\
\hline & 5 & 15 & 2 & $1.2536 \pm 0.03511$ & \\
\hline & -5 & 5 & 2 & $0.0514 \pm 0.02031$ & \\
\hline & -15 & -5 & 2 & $0.2557 \pm 0.00434$ & \\
\hline \multirow{4}{*}{$15^{\circ}$ convergence } & 0 & 15 & 2 & $0.5543 \pm 0.06516$ & \multirow{4}{*}{0.578} \\
\hline & -15 & 0 & 2 & $0.2959 \pm 0.02914$ & \\
\hline & -10 & 5 & 2 & $1.3048 \pm 1.78376$ & \\
\hline & -5 & 10 & 2 & $0.0418 \pm 0.03786$ & \\
\hline \multirow{3}{*}{$20^{\circ}$ convergence } & -15 & 5 & 2 & $0.0288 \pm 0.02071$ & \multirow{3}{*}{$0.005^{*}$} \\
\hline & -10 & 10 & 2 & $0.1081 \pm 0.02135$ & \\
\hline & -5 & 15 & 2 & $0.2477 \pm 0.02627$ & \\
\hline \multirow{2}{*}{$25^{\circ}$ convergence } & -15 & 10 & 2 & $0.0188 \pm 0.01102$ & \multirow{2}{*}{0.086} \\
\hline & -10 & 15 & 2 & $0.1059 \pm 0.03732$ & \\
\hline $30^{\circ}$ convergence & -15 & 15 & 2 & $0.6949 \pm 0.65102$ & - \\
\hline \multirow{5}{*}{$5^{\circ}$ divergence } & 0 & -5 & 2 & $0.3914 \pm 0.06898$ & \multirow{5}{*}{$<0.001^{*}$} \\
\hline & 5 & 0 & 2 & $0.9371 \pm 0.00040$ & \\
\hline & 10 & 5 & 2 & $0.0543 \pm 0.03306$ & \\
\hline & -5 & -10 & 2 & $0.7191 \pm 0.06766$ & \\
\hline & -10 & -15 & 2 & $0.9966 \pm 0.00399$ & \\
\hline \multirow{4}{*}{$10^{\circ}$ divergence } & 0 & -10 & 2 & $0.2709 \pm 0.05986$ & \multirow{4}{*}{$<0.001^{*}$} \\
\hline & 10 & 0 & 2 & $0.0660 \pm 0.01349$ & \\
\hline & 5 & -5 & 2 & $0.9406 \pm 0.09869$ & \\
\hline & -5 & -15 & 2 & $0.9709 \pm 0.06278$ & \\
\hline \multirow{3}{*}{$15^{\circ}$ divergence } & 0 & -15 & 2 & $0.7171 \pm 0.05593$ & \multirow{3}{*}{$0.014^{*}$} \\
\hline & 5 & -10 & 2 & $0.0940 \pm 0.09059$ & \\
\hline & 10 & -5 & 2 & $0.0728 \pm 0.06300$ & \\
\hline \multirow{2}{*}{$20^{\circ}$ divergence } & 5 & -15 & 2 & $0.0674 \pm 0.01360$ & 0007 \\
\hline & 10 & -10 & 2 & $1.0299 \pm 0.05283$ & 0.002 \\
\hline $25^{\circ}$ divergence & 10 & -15 & 2 & $1.1336 \pm 0.06927$ & - \\
\hline
\end{tabular}

Data presented as mean \pm standard deviation $(M \pm S D) .{ }^{*}$ statistically significant. 
According to the results of ANOVA and the $t$ test, a significant difference was observed in $5^{\circ}, 10^{\circ}$ and $20^{\circ}$ convergences, and in $5^{\circ}, 10^{\circ}, 15^{\circ}$, and $20^{\circ}$ divergences.

ANOVA showed that the parallel, convergent and divergent positions of the 2 implants relative to each other had no significant effect on the impression error $(p=0.251)$. The maximum mean impression error was noted in the $25^{\circ}$ divergent position of the 2 implants $(R=1.1336)$ (Table 2).

The effect of the angulation of implants 5 and 7 relative to the vertical axis on the impression error was significant $(p<0.0001)$ (Table 3$)$.

The results of the pairwise comparisons of different angulation with the use of Tukey's test did not show any significant differences in the 2 subgroups described below (implant 5 vs. implant 7):

- subgroup 1 (impression error range: 0.0188-0.3104): $-15^{\circ}$ vs. $10^{\circ} ;-10^{\circ}$ vs. $-5^{\circ} ;-15^{\circ}$ vs. $5^{\circ} ;-5^{\circ}$ vs. $10^{\circ} ;-5^{\circ}$ vs. $5^{\circ} ; 10^{\circ}$ vs. $5^{\circ} ;-10^{\circ}$ vs. $0^{\circ} ; 10^{\circ}$ vs. $0^{\circ} ;-5^{\circ}$ vs. $0^{\circ} ; 5^{\circ}$ vs. $-15^{\circ}$; $10^{\circ}$ vs. $10^{\circ}$; $10^{\circ}$ vs. $-5^{\circ}$; $10^{\circ}$ vs. $15^{\circ}$; $5^{\circ}$ vs. $-10^{\circ}$; $-10^{\circ}$ vs. $15^{\circ} ;-10^{\circ}$ vs. $10^{\circ} ;-5^{\circ}$ vs. $-5^{\circ} ;-5^{\circ}$ vs. $15^{\circ} ; 0^{\circ}$ vs. $10^{\circ} ;-15^{\circ}$ vs. $-5^{\circ} ; 0^{\circ}$ vs. $-10^{\circ} ;-15^{\circ}$ vs. $0^{\circ} ; 0^{\circ}$ vs. $0^{\circ}$; and - subgroup 2 (impression error range: $0.3914-1.3665$ ): $0^{\circ}$ vs. $-5^{\circ} ; 0^{\circ}$ vs. $5^{\circ} ; 0^{\circ}$ vs. $15^{\circ} ;-15^{\circ}$ vs. $15^{\circ} ; 5^{\circ}$ vs. $5^{\circ} ; 0^{\circ}$ vs. $-15^{\circ} ;-5^{\circ}$ vs. $-10^{\circ} ;-15^{\circ}$ vs. $-10^{\circ} ;-15^{\circ}$ vs. $-15^{\circ} ; 5^{\circ}$ vs. $10^{\circ} ; 5^{\circ}$ vs. $0^{\circ} ; 5^{\circ}$ vs. $-5^{\circ} ;-5^{\circ}$ vs. $-15^{\circ} ;-10^{\circ}$ vs. $-15^{\circ}$; $10^{\circ}$ vs. $-10^{\circ} ; 10^{\circ}$ vs. $-15^{\circ} ; 5^{\circ}$ vs. $15^{\circ} ;-10^{\circ}$ vs. $5^{\circ} ;-10^{\circ}$ vs. $-10^{\circ}$.

The impression technique (open- or closed-tray) had no significant effect on the impression error in different implant positions $(p=0.390)$. Accordingly, the mean error rate was $0.4460 \pm 0.4181$ in the open-tray technique and $0.5245 \pm 0.5095$ in the closed-tray technique. The difference in this respect between the 2 techniques was not significant $(p>0.05)$ (Table 4).

Table 2. Impression error values in the parallel, convergent and divergent positions of the 2 implants relative to each other

\begin{tabular}{|l|c|l|l|}
\multicolumn{1}{|c|}{ Position } & $\begin{array}{c}\text { Number } \\
\text { of positions }\end{array}$ & Impression error & $p$-value \\
\hline Parallel & 12 & $0.5761 \pm 0.54887$ \\
\hline $5^{\circ}$ convergence & 12 & $0.3810 \pm 0.37747$ \\
$10^{\circ}$ convergence & 10 & $0.3749 \pm 0.47262$ \\
$15^{\circ}$ convergence & 8 & $0.5492 \pm 0.84289$ \\
\hline $20^{\circ}$ convergence & 6 & $0.1282 \pm 0.10072$ \\
$25^{\circ}$ convergence & 4 & $0.0624 \pm 0.05505$ \\
\hline $30^{\circ}$ convergence & 2 & $0.6949 \pm 0.65102$ \\
\hline $5^{\circ}$ divergence & 10 & $0.6197 \pm 0.37407$ \\
$10^{\circ}$ divergence & 8 & $0.5621 \pm 0.43095$ \\
\hline $15^{\circ}$ divergence & 6 & $0.2946 \pm 0.33203$ \\
\hline $20^{\circ}$ divergence & 4 & $0.5486 \pm 0.55655$ \\
$25^{\circ}$ divergence & 2 & $1.1336 \pm 0.06927$ \\
\hline
\end{tabular}

Data presented as $M \pm S D$.
Table 3. Impression error values in different angular positions of implants 5 and 7 relative to the vertical axis of the implant (ANOVA)

\begin{tabular}{|c|c|c|c|}
\hline \multicolumn{2}{|c|}{$\begin{array}{c}\text { Angulation } \\
{\left[{ }^{\circ}\right]}\end{array}$} & \multirow{2}{*}{ Impression error } & \multirow[t]{2}{*}{$p$-value } \\
\hline implant 5 & implant 7 & & \\
\hline 0 & 0 & $0.3104 \pm 0.04178$ & \multirow{42}{*}{$0.0001^{*}$} \\
\hline 5 & 5 & $0.7112 \pm 0.53412$ & \\
\hline 10 & 10 & $0.0690 \pm 0.01858$ & \\
\hline-5 & -5 & $0.1150 \pm 0.00000$ & \\
\hline-10 & -10 & $1.3665 \pm 0.67123$ & \\
\hline-15 & -15 & $0.8849 \pm 0.13626$ & \\
\hline 0 & 5 & $0.4360 \pm 0.00994$ & \\
\hline 0 & 10 & $0.2524 \pm 0.01513$ & \\
\hline 0 & 15 & $0.5543 \pm 0.06516$ & \\
\hline 0 & -5 & $0.3914 \pm 0.06898$ & \\
\hline 0 & -10 & $0.2709 \pm 0.05986$ & \\
\hline 0 & -15 & $0.7171 \pm 0.05593$ & \\
\hline 5 & 0 & $0.9371 \pm 0.00040$ & \\
\hline 10 & 0 & $0.0660 \pm 0.01349$ & \\
\hline-5 & 0 & $0.0662 \pm 0.02394$ & \\
\hline-10 & 0 & $0.0614 \pm 0.00740$ & \\
\hline-15 & 0 & $0.2959 \pm 0.02914$ & \\
\hline 5 & 10 & $0.9317 \pm 0.16470$ & \\
\hline 5 & 15 & $1.2536 \pm 0.03511$ & \\
\hline 5 & -5 & $0.9406 \pm 0.09869$ & \\
\hline 5 & -10 & $0.0940 \pm 0.09059$ & \\
\hline 5 & -15 & $0.0674 \pm 0.01360$ & \\
\hline 10 & 5 & $0.0543 \pm 0.03306$ & \\
\hline-5 & 5 & $0.0514 \pm 0.02031$ & \\
\hline-10 & 5 & $1.3048 \pm 1.78376$ & \\
\hline-15 & 5 & $0.0288 \pm 0.02071$ & \\
\hline 10 & 15 & $0.0739 \pm 0.01089$ & \\
\hline 10 & -5 & $0.0728 \pm 0.06300$ & \\
\hline 10 & -10 & $1.0299 \pm 0.05283$ & \\
\hline 10 & -15 & $1.1336 \pm 0.06927$ & \\
\hline-5 & 10 & $0.0418 \pm 0.03786$ & \\
\hline-10 & 10 & $0.1081 \pm 0.02135$ & \\
\hline-15 & 10 & $0.0188 \pm 0.01102$ & \\
\hline-5 & 15 & $0.2477 \pm 0.02627$ & \\
\hline-10 & 15 & $0.1059 \pm 0.03732$ & \\
\hline-15 & 15 & $0.6949 \pm 0.65102$ & \\
\hline-5 & -15 & $0.9709 \pm 0.06278$ & \\
\hline-10 & -5 & $0.0229 \pm 0.01042$ & \\
\hline-15 & -5 & $0.2557 \pm 0.00434$ & \\
\hline-5 & -10 & $0.7191 \pm 0.06766$ & \\
\hline-10 & -15 & $0.9966 \pm 0.00399$ & \\
\hline-15 & -10 & $0.7555 \pm 0.05273$ & \\
\hline
\end{tabular}

Data presented as $M \pm S D$. * statistically significant. 
Table 4. Mean impression error values in the open- and closed-tray techniques

\begin{tabular}{|c|c|c|c|}
\hline \multicolumn{2}{|c|}{$\begin{array}{c}\text { Angulation } \\
{\left[^{\circ}\right]}\end{array}$} & \multirow{2}{*}{$\begin{array}{l}\text { Open-tray } \\
\text { technique }\end{array}$} & \multirow{2}{*}{$\begin{array}{l}\text { Closed-tray } \\
\text { technique }\end{array}$} \\
\hline implant 5 & implant 7 & & \\
\hline 0 & 0 & 0.2808 & 0.3399 \\
\hline 5 & 5 & 0.3335 & 1.0889 \\
\hline 10 & 10 & 0.0558 & 0.0821 \\
\hline-5 & -5 & 0.1150 & 0.1150 \\
\hline-10 & -10 & 1.8411 & 0.8918 \\
\hline-15 & -15 & 0.9812 & 0.7885 \\
\hline 0 & 5 & 0.4431 & 0.4290 \\
\hline 0 & 10 & 0.2417 & 0.2631 \\
\hline 0 & 15 & 0.5082 & 0.6004 \\
\hline 0 & -5 & 0.3427 & 0.4402 \\
\hline 0 & -10 & 0.2286 & 0.3132 \\
\hline 0 & -15 & 0.6776 & 0.7567 \\
\hline 5 & 0 & 0.9374 & 0.9369 \\
\hline 10 & 0 & 0.0756 & 0.0565 \\
\hline-5 & 0 & 0.0831 & 0.0492 \\
\hline-10 & 0 & 0.0667 & 0.0562 \\
\hline-15 & 0 & 0.2753 & 0.3166 \\
\hline 5 & 10 & 1.0482 & 0.8152 \\
\hline 5 & 15 & 1.2287 & 1.2784 \\
\hline 5 & -5 & 1.0104 & 0.8709 \\
\hline 5 & -10 & 0.0229 & 0.1581 \\
\hline 5 & -15 & 0.0770 & 0.0578 \\
\hline 10 & 5 & 0.0777 & 0.0310 \\
\hline-5 & 5 & 0.0657 & 0.0370 \\
\hline-10 & 5 & 0.0435 & 2.5661 \\
\hline-15 & 5 & 0.0434 & 0.0141 \\
\hline 10 & 15 & 0.0662 & 0.0816 \\
\hline 10 & -5 & 0.0282 & 0.1173 \\
\hline 10 & -10 & 0.9925 & 1.0672 \\
\hline 10 & -15 & 1.0846 & 1.1826 \\
\hline-5 & 10 & 0.0151 & 0.0686 \\
\hline-10 & 10 & 0.1231 & 0.0930 \\
\hline-15 & 10 & 0.0111 & 0.0266 \\
\hline-5 & 15 & 0.2291 & 0.2663 \\
\hline-10 & 15 & 0.0795 & 0.1323 \\
\hline-15 & 15 & 0.2346 & 1.1552 \\
\hline-5 & -15 & 0.9265 & 1.0153 \\
\hline-10 & -5 & 0.0155 & 0.0302 \\
\hline-15 & -5 & 0.2587 & 0.2526 \\
\hline-5 & -10 & 0.6713 & 0.7670 \\
\hline-10 & -15 & 0.9938 & 0.9995 \\
\hline-15 & -10 & 0.7182 & 0.7928 \\
\hline & & 0.4181 & 0.5095 \\
\hline
\end{tabular}

\section{Discussion}

Several methods are employed to achieve passive fit in implant-supported restorations. An accurate impression without distortion is imperative to precisely reproduce the position of implants on casts. Considering the problems encountered when making the impressions of angulated implants, this study assessed the effect of dental implant angulation on the dimensional accuracy of master casts and showed that the angulation of the 2 implants (5 and 7) relative to their longitudinal axis in different positions had a significant effect on the dimensional accuracy of the final casts. Conversely, the effect of the impression technique (open- or closed-tray) in the parallel, convergent and divergent positions of the implants on the impression error was not significant. In other words, implant angulation affected the impression error.

Errors in impression making may be related to the type of impression material, the technique of impression making, the performance of the dentist, the incorrect position of impression copings, and the incorrect attachment of implant components. Although the passive fit of implants has been the topic of many investigations, the clinical significance of dimensional changes or distortion has not been adequately emphasized. Also, the acceptable range of errors in the transfer of the intraoral implant position to the dental cast has not been determined yet. The findings of this study were related to the placement of implants 5 and 7 in 42 different positions at the $-15^{\circ},-10^{\circ},-5^{\circ}, 0^{\circ}, 5^{\circ}, 10^{\circ}$, and $15^{\circ}$ angles relative to their longitudinal axis, and may not be generalizable to a higher number or other angulation of implants. However, it seems that other angulation has limited application in the clinical setting.

In this study, no specific ascending or descending patterns were noted regarding the impression error in the different angulation of the 2 implants to obtain a definite conclusion in this respect. However, in total, the effect of implant angulation on the impression error was significant $(p=0.0001)$. The significant effect of implant angulation on the dimensional accuracy of the final casts highlights the importance of this topic, especially because implants are placed in angulated positions in many patients. Despite the significance of this topic, studies addressing this issue are limited. $\mathrm{Carr}^{17}$ and Assuncao et al. ${ }^{18}$ reported that angulated implants had lower dimensional accuracy than straight implants, while another study evaluating 3 implants determined that the implant angle had no significant effect on the dimensional accuracy of casts. ${ }^{19}$ It seems that when a higher number of implants with different angulation is used, the dimensional changes of the impression material increase. ${ }^{4}$ Conrad et al. evaluated the accuracy of impression techniques when 3 angulated implants were placed at 3 corners of a triangle at angles of $5^{\circ}, 10^{\circ}$ and $15^{\circ}$ (convergent or divergent relative to the central implant). ${ }^{4}$ They dem- 
onstrated that the implant angle had a significant effect on the dimensional accuracy of casts. ${ }^{4}$ Their findings are in line with the present study, although we used 2 implants and evaluated the $0^{\circ}$ angle as well. Carr compared the dimensional accuracy of the final casts obtained with 2 impression techniques for 2 divergent implants $\left(15^{\circ}\right) .{ }^{17}$ The author showed that this divergence had no significant effect on the dimensional accuracy of impressions. However, straight implants had slightly higher dimensional accuracy than angulated implants. This finding was attributed to the proximity of implant locations $(11 \mathrm{~mm})$. In contrast to the present study, the author evaluated only one implant angle. ${ }^{17}$ Choi et al. assessed the accuracy of 2 impression techniques for parallel or $8^{\circ}$ divergent internal hexagonal implants, and showed that the accuracy of implant impressions was the same in both impression techniques and a degree of divergence up to $8^{\circ}$ had no significant effect on the accuracy of impressions. ${ }^{19}$ The non-significant effect of the degree of convergence/divergence on the dimensional accuracy of impressions was confirmed in this study.

This study found no significant difference in the dimensional accuracy of the casts when the open- and closedtray impression techniques were compared. A review of the literature revealed that in the presence of 4 or more implants, the open-tray technique often provides higher accuracy than the closed-tray technique. ${ }^{20}$ However, studies on 3 or fewer implants mainly found no significant difference between the impression techniques in terms of dimensional accuracy. ${ }^{7,10,17}$ The results of the current study confirm this finding. Since some degrees of error and deformity are inevitable in both techniques, attempts must be made to minimize distortion during different phases of impression making as well as during the transfer of the implant position to the final cast in order to fabricate stress-free implant-supported restorations. ${ }^{21,22}$ Carr found no significant difference between the openand closed-tray impression techniques when making the impressions of 2 implants with $15^{\circ}$ divergence. ${ }^{17}$ Conrad et al. evaluated 3 implants and reported a similar level of distortion and deformity for the 2 impression techniques. ${ }^{4}$ Herbst et al. found no significant difference in dimensional accuracy between different impression techniques. $^{7}$

Similar to previous research, this study showed that the distances measured on the original model could not be ideally transferred to the final cast, and that the spatial coordinates of the implants changed relative to each other when transferred to the cast. ${ }^{10,23,24}$ The reason might be the movement of the metal copings when opening or closing the guiding rods or attaching the analog, ${ }^{10,25}$ the dimensional changes of the gypsum, ${ }^{26}$ the shrinkage of the acrylic resin when the copings were connected to each other, ${ }^{10,25,26}$ changes in the impression material, ${ }^{25}$ the depth of implant placement, ${ }^{27}$ soft tissue adhesion (since it could modify the mucosal aspect around the implant), ${ }^{28}$ the duration of the use of the dental stone, ${ }^{29}$ the implant-abutment interface, ${ }^{30}$ machining tolerance $(0.6-136 \mu \mathrm{m}),{ }^{20}$ or the operator's error, which is minimally $30 \mu \mathrm{m}$ in the laboratory setting, but may increase in the oral environment. ${ }^{31}$ Moreover, different methodologies can yield variable results. The designed experimental models (metal or acrylic), different measuring devices, the distances measured relative to the reference points, and different methods of attachment of metal copings can all affect the results. Also, some studies measured the distances in only the $\mathrm{X}$ and $\mathrm{Y}$ dimensions, while others, including the current study, measured dimensional changes in all 3 dimensions of $\mathrm{X}, \mathrm{Y}$ and $\mathrm{Z}$, and calculated the spatial position (R), which would enhance the comparison of the results of studies.

There are limitations to this study. It evaluated only 2 implants in a limited range of angulation. Also, the effect of the type of impression material on the dimensional accuracy of casts was not evaluated. Future studies with a higher number of implants, a larger range of angulation $\left(>15^{\circ}\right)$ and different impression materials are required to better elucidate this topic and find a definite conclusion, generalizable to the clinical setting while controlling for a higher number of confounders.

\section{Conclusions}

Within the limitations of this in vitro study, the results showed a significant effect of implant angulation (implants 5 and 7) in the range from $-15^{\circ}$ to $+15^{\circ}$ on the dimensional accuracy of impressions. The open- and closed-tray techniques were not significantly different in this respect. Under similar conditions, it seems that the closed-tray technique may be preferred due to the ease of use, patient comfort and accuracy comparable to that obtained with the open-tray technique.

\section{ORCID iDs}

Negar Barjini (1) https://orcid.org/0000-0002-4193-3195

Sahar Sayahpour (1) https://orcid.org/0000-0002-6720-082X

Maryam Jafari (i) https://orcid.org/0000-0002-1831-2219

\section{References}

1. Papaspyridakos P, Chen CJ, Gallucci GO, Doukoudakis A, Weber HP, Chronopoulos V. Accuracy of implant impressions for partially and completely edentulous patients: A systematic review. Int J Oral Maxillofac Implants. 2014;29(4):836-845. doi:10.11607/jomi.3625

2. Al Quran FA, Rashdan BA, Abu Zomar AA, Weiner S. Passive fit and accuracy of three dental implant impression techniques. Quintessence Int. 2012;43(2):119-125. PMID:22257873.

3. Hanif A, Qureshi S, Sheik Z, Rashid H. Complications in implant dentistry. Eur J Dent. 2017;11(1):135-140. doi:10.4103/ejd.ejd_340_16

4. Conrad HJ, Pesun IJ, DeLong R, Hodges JS. Accuracy of two impression techniques with angulated implants. J Prosthet Dent. 2007;97(6):349-356. doi:10.1016/S0022-3913(07)60023-7

5. Bonfante $E A$, Jimbo $R$, Witek $L$, et al. Biomaterial and biomechanical considerations to prevent risks in implant therapy. Periodontol 2000. 2019;81(1):139-151. doi:10.1111/prd.12288 
6. Schmidt A, Billig JW, Schlenz MA, Wöstmann B. A new 3D-method to assess the inter implant dimensions in patients - a pilot study. J Clin Exp Dent. 2020;12(2):e187-e192. doi:10.4317/jced.56557

7. Herbst D, Nel JC, Driessen CH, Becker PJ. Evaluation of impression accuracy for osseointegrated implant supported superstructures. J Prosthet Dent. 2000;83(5):555-561. doi:10.1016/s0022-3913(00)70014-x

8. Richi MW, Kurtulmus-Yilmaz S, Ozan O. Comparison of the accuracy of different impression procedures in case of multiple and angulated implants: Accuracy of impressions in multiple and angulated implants. Head Face Med. 2020;16(1):9. doi:10.1186/s13005-020-00225-3

9. Selvaraj S, Dorairaj J, Mohan J, Simon P. Comparison of implant cast accuracy of multiple implant impression technique with different splinting materials: An in vitro study. J Indian Prosthodont Soc. 2016;16(2):167-175. doi:10.4103/0972-4052.167937

10. Spector MR, Donovan TE, Nicholls Jl. An evaluation of impression techniques for osseointegrated implants. J Prosthet Dent. 1990;63(4):444-447. doi:10.1016/0022-3913(90)90235-5

11. Tabesh M, Alikhasi M, Siadat H. A comparison of implant impression precision: Different materials and techniques. J Clin Exp Dent. 2018;10(2):e151-e157. doi:10.4317/jced.54457

12. Patil R, Kadam P, Oswal C, Patil S, Jajoo S, Gachake A. A comparative analysis of the accuracy of implant master casts fabricated from two different transfer impression techniques. J Int Soc Prev Community Dent. 2016;6(2):142-148. doi:10.4103/2231-0762.178747

13. Ribeiro $P$, Herrero-Climent $M$, Diáz-Castro $C$, et al. Accuracy of implant casts generated with conventional and digital impressions - an in vitro study. Int J Environ Res Public Health. 2018;15(8):1599. doi:10.3390/ijerph15081599

14. Stimmelmayr M, Erdelt K, Güth JF, Happe A, Beuer F. Evaluation of impression accuracy for a four-implant mandibular model - a digital approach. Clin Oral Investig. 2012;16(4):1137-1142. doi:10.1007/s00784-011-0622-z

15. Selecman AM, Wicks RA. Making an implant-level impression using solid plastic, press-fit, closed-tray impression copings: A clinical report. J Prosthet Dent. 2009;101(3):158-159. doi:10.1016/S0022-3913(09)60020-2

16. Ghahremanloo A, Seifi M, Ghanbarzade J, Abrisham SM, Javan RA Effect of polyvinyl siloxane viscosity on accuracy of dental implant impressions. J Dent (Tehran). 2017;14(1):40-47. PMID:28828016. PMCID:PMC5557995.

17. Carr AB. Comparison of impression techniques for a two-implant 15-degree divergent model. Int J Oral Maxillofac Implants. 1992;7(4):468-475. PMID:1299642.

18. Assuncao WG, Filho HG, Zaniquelli O. Evaluation of transfer impressions for osseointegrated implants at various angulations. Implant Dent. 2004;13(4):358-366. doi:10.1097/01.id.0000144509.58901.f7

19. Choi JH, Lim YJ, Yim SH, Kim CW. Evaluation of the accuracy of implant-level impression techniques for internal-connection implant prostheses in parallel and divergent models. Int J Oral Maxillofac Implants. 2007;22:761-768. PMID:17974110.

20. Arora A, Upadhyaya V, Parashar KR, Malik D. Evaluation of the effect of implant angulations and impression techniques on implant cast accuracy - an in vitro study. J Indian Prosthodont Soc. 2019;19(2):149-158. doi:10.4103/jips.jips_337_18

21. Buzayan MM, Yunus NB. Passive fit in screw retained multiunit implant prosthesis understanding and achieving: A review of the literature. J Indian Prosthodont Soc. 2014;14(1):16-23. doi:10.1007/s13191-013-0343-x

22. Mobilio N, Fasiol A, Franceschetti G, Catapano S. Marginal vertical fit along the implant-abutment interface: A microscope qualitative analysis. Dent J (Basel). 2016;4(3):31. doi:10.3390/dj4030031

23. Menini M, Setti P, Pera F, Pera P, Pesce P. Accuracy of multi-unit implant impression: Traditional techniques versus a digital procedure. Clin Oral Investig. 2018;22(3):1253-1262. doi:10.1007/s00784-017-2217-9

24. Lee SE, Yang SE, Lee CW, Lee WS, Lee SY. Accuracy of new implant impression technique using dual arch tray and bite impression coping. J Adv Prosthodont. 2018;10(4):265-270. doi:10.4047/jap.2018.10.4.265

25. Chang WG, Vahidi F, Bae KH, Lim BS. Accuracy of three implant impression techniques with different impression materials and stones. Int J Prosthodont. 2012;25(1):44-47. PMID:22259795.

26. Nakhaei M, Madani AS, Moraditalab A, Haghi HR. Three-dimensional accuracy of different impression techniques for dental implants. Dent Res J (Isfahan). 2015;12(5):431-437. doi:10.4103/1735-3327.166190
27. Bartlett DW, Greenwood R, Howe L. The suitability of head-ofimplant and conventional abutment impression techniques for implant-retained three unit bridges: An in vitro study. Eur J Prosthodont Restor Dent. 2002;10(4):163-166. PMID:12526273.

28. Guarnieri R, Di Nardo D, Gaimari G, Miccoli G, Testarelli L. Implant-gingival unit stability around one-stage implant with laser-microgrooved collar: Three-year result of a prospective study. Int J Periodontics Restorative Dent. 2019;39(6):875-882. doi:10.11607/prd.3983

29. Gupta S, Narayan Al, Balakrishnan D. In vitro comparative evaluation of different types of impression trays and impression materials on the accuracy of open tray implant impressions: A pilot study. Int J Dent. 2017;2017:6306530. doi:10.1155/2017/6306530

30. Ebadian B, Rismanchian M, Dastgheib B, Bajoghli F. Effect of different impression materials and techniques on the dimensional accuracy of implant definitive casts. Dent Res J (Isfahan). 2015;12(2):136-143. PMID:25878678. PMCID:PMC4387625.

31. Deogade SC, Dube G. A sectional-splinting technique for impressing multiple implant units by eliminating the use of an open tray. Contemp Clin Dent. 2014;5(2):221-226. doi:10.4103/0976-237X.132347 